\title{
Replacement of Steel by Bamboo Reinforcement
}

\author{
Anurag Nayak ${ }^{1}$, Arehant S Bajaj ${ }^{2}$, Abhishek Jain ${ }^{3}$, Apoorv Khandelwal ${ }^{4}$, \\ Hirdesh Tiwari ${ }^{5}$ \\ ${ }^{1,3,4,5}$ (Department of Civil Engineering, Sanghvi Institute of Management \& Science Behind IIM-Indore, \\ Pigdambar, 453331, Indore, India) \\ ${ }^{2}$ (Department of Civil Engineering, ME-Structures, S. G.S.I.T.S, Indore, India)
}

\begin{abstract}
The present paper deals with cost-wise comparison of steel reinforcement with bamboo reinforcement. The utilization of bamboo reinforcement as replacement of steel reinforcement is gaining immense importance today, mainly on account of the improvement in the economical aspect combined with ecological benefits.

To study the effect of replacement of steel reinforcement by bamboo reinforcement, designs have been conducted on one way slab of size $3000 \times 7000 \mathrm{sq}-\mathrm{mm}$ with providing beam of $7000 \mathrm{~mm}$ length and $250 \times 250$ sq-mm. In this paper the designs are done on the basis of shearing and bending. Based on this study of cost vs strength provided results have been discussed in the paper.
\end{abstract}

Keywords: Bamboo, Flexural Strength, Cost Estimation, Economical.

\section{Introduction}

The world timber demand is increasing at a rapid rate but the timber supply is depleting. It's been found through research that bamboo can suitably replace timber and other materials in construction and other works. Industrially treated bamboo has shown great potential for production of composite materials and components which are cost-effective and can be successfully utilized for structural and non-structural applications in construction. Bamboo is one of the oldest traditional building materials used by mankind.

The bamboo culm, or stem, has been made into an extended diversity of products ranging from domestic household products to industrial applications. Bamboo is quite common for bridges, scaffolding and housing, but it is usually used as a temporary exterior structural material. In many overly populated regions of the tropics, certain bamboos supply the one suitable material that is sufficiently cheap and plentiful to meet the extensive need for economical housing.

With the advancement of science and technology and the tight supply of timber, new methods are needed for the processing of bamboo to make it more durable and more usable in terms of building materials. Studies have been carried out on the basic properties and on processing of bamboo into various kinds of composite products. Bamboo has several unique advantages like ability to grow fast with a high yield and also it matures quickly. Additionally bamboo can be grown abundantly and that too at a lower cost which makes it more economical.

\section{Bamboo As Construction Material}

Through research it has been found that some species of bamboo have ultimate tensile strength same as that of mild steel at yield point. Experimentally it has been found that the ultimate tensile strength of some species of bamboo is comparable to that of mild steel and it varies from $140 \mathrm{~N} / \mathrm{mm} 2-280 \mathrm{~N} / \mathrm{mm} 2$. Bamboo is a versatile material because of its high strength-to-weight ratio, easy workability and availability. Bamboo needs to be chemically treated due to their low natural durability. It can be used as Bamboo Trusses, Bamboo Roofs Skeleton, Bamboo walling/ceiling, Bamboo Doors and Windows, Bamboo Flooring, Reed Boards, Scaffolding.

\section{II.I. Strength Properties of Bamboo}

It has also been found that bamboo acts very well in buckling but due to low stresses than compared to steel and due to it not being straight it may not be very good. Further, it has been established that in seismic zones the failure of bamboo is very less as the maximum absorption of the energy is at the joints. Cellulose is the main component present in bamboo which is the main source of mechanical properties of bamboo.

Some specific properties of Bamboo are as given below:

- Specific gravity -0.575 to 0.655

- Average weight $-0.625 \mathrm{~kg} / \mathrm{m}$

- Modulus of rupture - 610 to $1600 \mathrm{~kg} / \mathrm{cm} 2$

- Modulus of Elasticity -1.5 to $2.0 \times 105 \mathrm{~kg} / \mathrm{cm} 2$ 
- Ultimate compressive stress- 794 to $864 \mathrm{~kg} / \mathrm{cm} 2$

- Safe working stress in compression $-105 \mathrm{~kg} / \mathrm{cm} 2$

Safe working stress in tension It has also been found that bamboo acts very well in buckling but due to low stresses than compared to steel and due to it not being straight it may not be very good.

Further, it has been established that in seismic zones the failure of bamboo is very less as the maximum absorption of the energy is at the joints. Cellulose is the main component present in bamboo which is the main source of mechanical properties of bamboo.

Some specific properties of Bamboo are as given below:

- $\quad$ Specific gravity -0.575 to 0.655

- Average weight $-0.625 \mathrm{~kg} / \mathrm{m}$

- Modulus of rupture -610 to $1600 \mathrm{~kg} / \mathrm{cm} 2$

- Modulus of Elasticity - 1.5 to $2.0 \times 105 \mathrm{~kg} / \mathrm{cm} 2$

- Ultimate compressive stress- 794 to $864 \mathrm{~kg} / \mathrm{cm} 2$

- Safe working stress in compression $-105 \mathrm{~kg} / \mathrm{cm} 2$

- Safe working stress in tension - 160 to $350 \mathrm{~kg} / \mathrm{cm}^{2}$

- Safe working stress in shear- 115 to $180 \mathrm{~kg} / \mathrm{cm}^{2}$

- Bond stress $-5.6 \mathrm{~kg} / \mathrm{cm}^{2}$

\section{II.II. Selection And Preparation Of Bamboo Selection}

The following factors should be considered in the selection of bamboo culms (whole plants) for use as reinforcement in concrete structures:

- Use only bamboo showing a pronounced brown colour. This will insure that the plant is at least three years old.

- Select the longest large diameter culms available.

- Do not use whole culms of green, unseasoned bamboo.

- Avoid bamboo cut in spring or early summer. These culms are generally weaker due to increased fibre moisture content.

\section{Preparation}

- Sizing- Splints are generally more desirable than whole culms as reinforcement. Larger culms should be split into splints approximately $3 / 4$ inch wide. Whole culms less than $3 / 4$ inch in diameter can be used without splitting.

Splitting the bamboo can he done by separating the base with a sharp knife and then pulling a dulled blade through the stem. The dull blade will force the stem to split open; this is more desirable than cutting the bamboo since splitting will result in continuous fibres and a nearly straight section

- Seasoning- When possible, the bamboo should be cut and allowed to dry and season for three to four weeks before using. The culms must be supported at regular spacing's to reduce warping.

- Waterproof Coatings- When seasoned bamboo, either split or whole is used as reinforcement; it should receive a waterproof coating to reduce swelling when in contact with concrete. Without some type of coating, bamboo will swell before the concrete has developed sufficient strength to prevent cracking and the member may be damaged, especially if more than 4 percent bamboo is used.

\section{II.III. Construction Principles}

In general, techniques used in conventional reinforced concrete construction need not he changed when bamboo is to be used for reinforcement.

Concrete Mix Proportions - The same mix designs can be used as would normally be used with steel reinforced concrete. Concrete slump should be as low as workability will allow. Excess water causes swelling of the bamboo. High early-strength cement is preferred to minimize cracks caused by swelling of bamboo when seasoned bamboo cannot be waterproofed.

Placement of bamboo- Bamboo reinforcement should not be placed less than 1.5 inches from the face of the concrete surface. When using whole culms, the top and bottom of the stems should be alternated in every row and the nodes or collars, should be staggered. This will insure a fairly uniform cross section of the bamboo 
throughout the length of the member, and the wedging effect obtained at the nodes will materially increase the bond between concrete and bamboo.

The clear spacing between bamboo rods or splints should not be less than the maximum size aggregate plus $1 / 4$ inch. Reinforcement should be evenly spaced and lashed together on short sticks placed at right angles to the main reinforcement. When more than one layer is required, the layers should also be tied together. Ties should preferably be made with wire in important members. For secondary members, ties can be made with vegetation strips.

Bamboo must be securely tied down before placing the concrete. It should be fixed at regular intervals of 3 to 4 feet to prevent it from floating up in the concrete during placement and vibration. In flexural members continuous, one-half to two-thirds of the bottom longitudinal reinforcement should be bent up near the supports. This is especially recommended in members continuous over several supports. Additional diagonal tension reinforcement in the form of stirrups must be used near the supports. The vertical stirrups can be made from wire or packing case straps when available; they can also be improvised from split sections of bamboo bent into U-shape, and tied securely to both bottom longitudinal reinforcement and bent-up reinforcement. Spacing of the stirrups should not exceed 6 inches.

\section{Tables \& Graphs}

\section{III.I Properties of bamboo and steel reinforcing bars}

\section{Bamboo}

\begin{tabular}{|c|c|}
\hline \multicolumn{2}{|c|}{ Whole Culms } \\
\hline Diameter (in.) & Area (sq. in.) \\
\hline $3 / 8$ & 0.008 \\
\hline $1 / 2$ & 0.136 \\
\hline $5 / 8$ & 0.239 \\
\hline $3 / 4$ & 0.322 \\
\hline 1 & 0.548 \\
\hline 2 & 1.92 \\
\hline
\end{tabular}

\begin{tabular}{|c|c|}
\hline \multicolumn{2}{|c|}{ 3/4 Inch Wide Splints } \\
\hline Thickness (in.) & Area (sq. in.) \\
\hline $1 / 8$ & 0.094 \\
\hline $1 / 4$ & 0.188 \\
\hline $3 / 8$ & 0.282 \\
\hline $1 / 2$ & 0.375 \\
\hline $5 / 8$ & 0.469 \\
\hline $3 / 4$ & 0.563 \\
\hline
\end{tabular}

\section{Steel Reinforcement}

\begin{tabular}{|c|c|c|}
\hline \multicolumn{3}{|c|}{ Nominal Dimensions - Round Sections } \\
\hline Bar Designation No. & Nominal Diameter (in.) & Cross Sectional. Area (sq. in.) \\
\hline 2 & 0.250 & 0.05 \\
\hline 3 & 0.375 & 0.11 \\
\hline 4 & 0.500 & 0.20 \\
\hline 5 & 0.625 & 0.31 \\
\hline 6 & 0.750 & 0.44 \\
\hline 7 & 0.875 & 0.60 \\
\hline 8 & 1.000 & 0.79 \\
\hline 9 & 1.128 & 1.00 \\
\hline 10 & 1.270 & 1.27 \\
\hline 11 & 1.410 & 1.56 \\
\hline
\end{tabular}

\section{Steel Wire}

\begin{tabular}{|c|c|c|c|}
\hline AS\&W Wire Gauge Numbers & Diameter (in) & Area (sq. in.) & Weight (lb/ft) \\
\hline 0000 & 0.3938 & 0.12180 & 0.4136 \\
\hline 000 & 0.3625 & 0.10321 & 0.3505 \\
\hline 00 & 0.3310 & 0.086049 & 0.2922 \\
\hline 0 & 0.3065 & 0.073782 & 0.2506 \\
\hline 1 & 0.2830 & 0.062902 & 0.2136 \\
\hline 2 & 0.2625 & 0.054119 & 0.1838 \\
\hline 3 & 0.2437 & 0.046645 & 0.1584 \\
\hline 4 & 0.2253 & 0.039867 & 0.1354 \\
\hline 5 & 0.2070 & 0.033654 & 0.1143 \\
\hline 6 & 0.1920 & 0.028953 & 0.09832 \\
\hline
\end{tabular}


Replacement Of Steel By Bamboo Reinforcement

\begin{tabular}{|c|c|c|c|}
\hline 7 & 0.1770 & 0.024606 & 0.08356 \\
\hline 8 & 0.1620 & 0.020612 & 0.07000 \\
\hline 9 & 0.1483 & 0.017273 & 0.05866 \\
\hline 10 & 0.1350 & 0.014314 & 0.04861 \\
\hline 11 & 0.1205 & 0.011404 & 0.03873 \\
\hline 12 & 0.1055 & 0.0087417 & 0.02969 \\
\hline 13 & 0.0915 & 0.0065755 & 0.02233 \\
\hline 15 & 0.0800 & 0.0050266 & 0.01707 \\
\hline
\end{tabular}

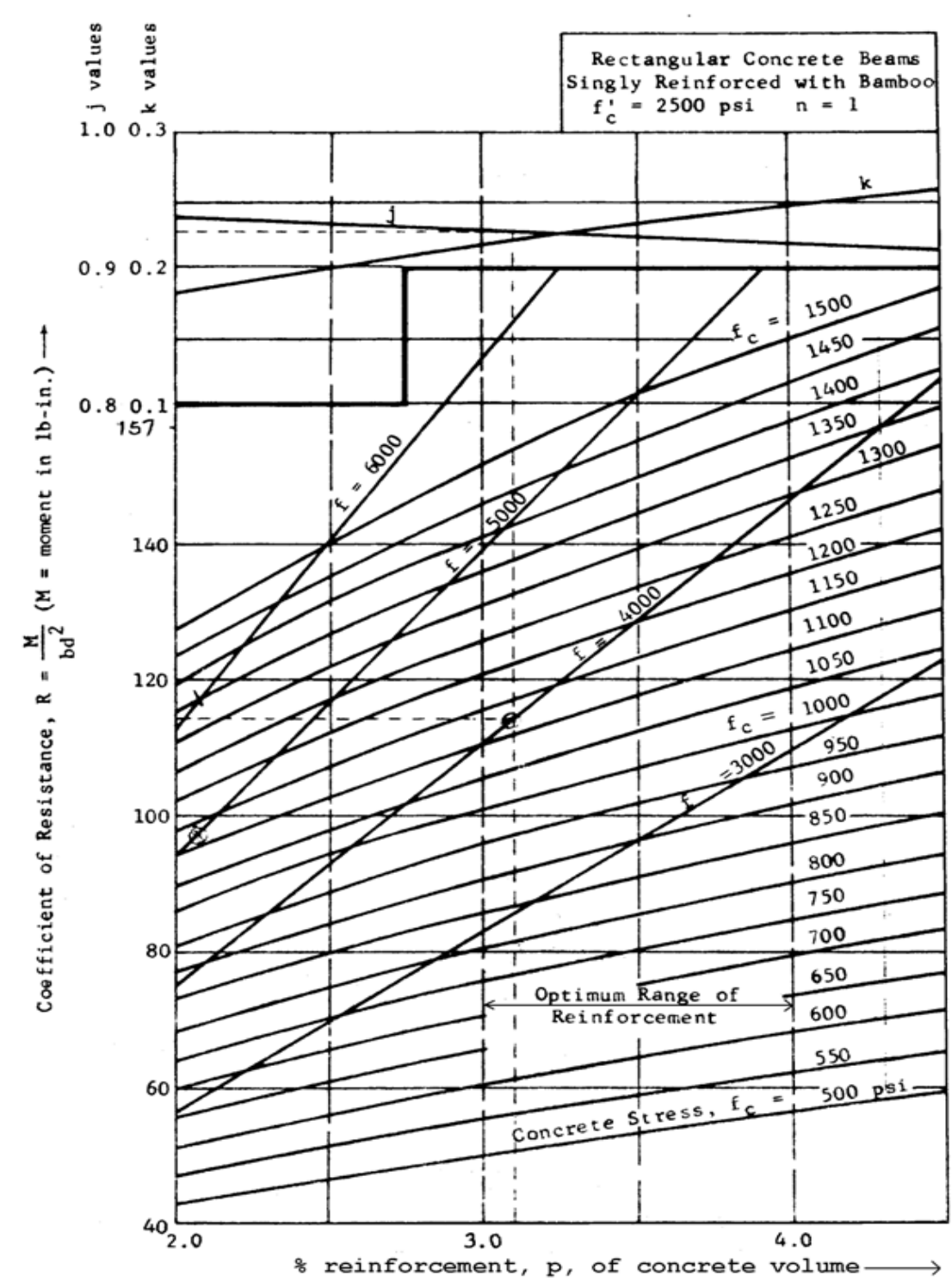

Figure 1- Resistance coefficients for bamboo reinforced concrete beams and their flexural Member. 

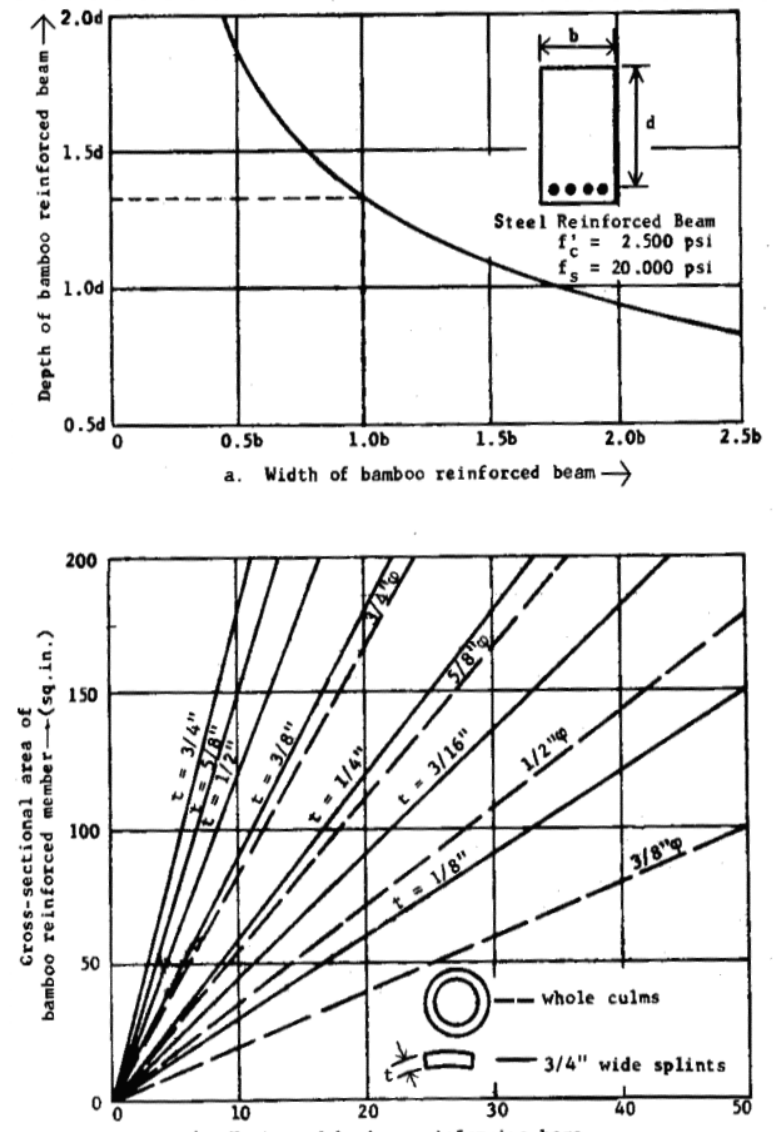

b. Number of bamboo reinforcing bars $\rightarrow$

(Number of bamboo reinforcing bars plotted will provide a member

with $3 \%$ reinforcement. For other percentage requirements.

Figure 2- Bamboo substitute beams and reinforcement.

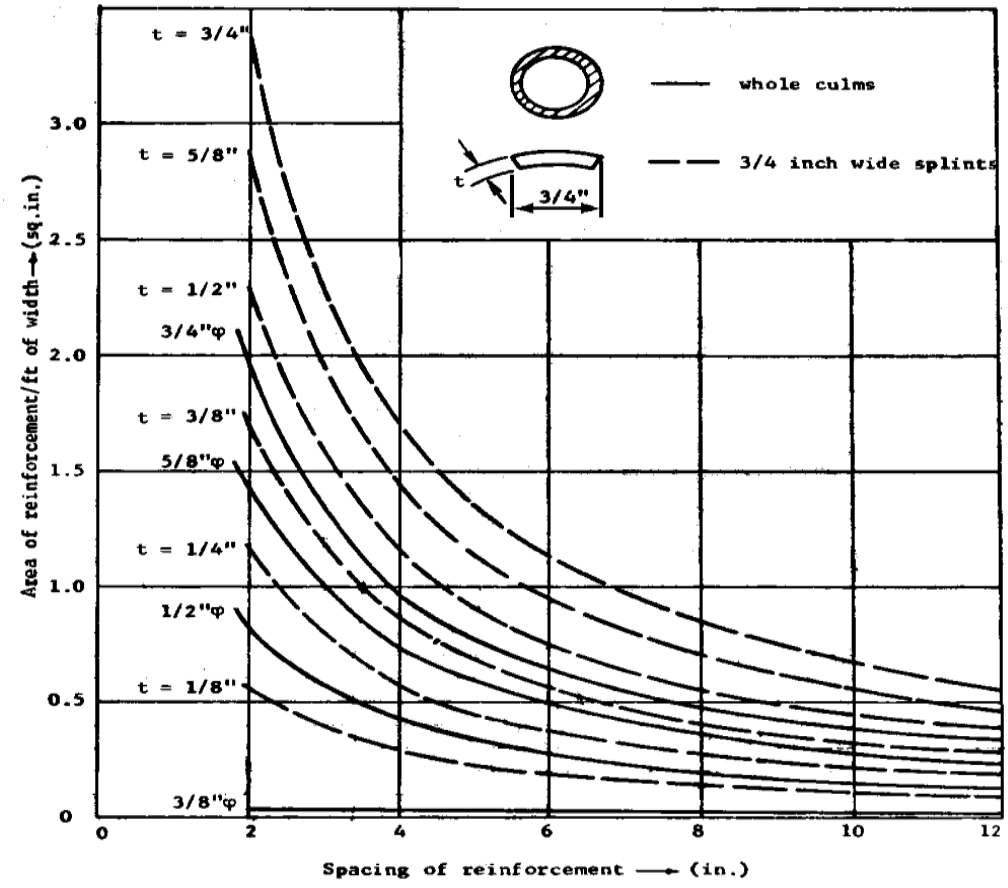

Figure 3- Size and spacing of bamboo reinforcement in slabs and walls. 


\section{IV.I. Introduction}

\section{Research Methodology}

To show the advantage of bamboo reinforcement in place of steel, building components are designed using steel and bamboo as a reinforcement. Further estimation of reinforcement is done.

- In this project we have opted advanced bamboo reinforcement technique instead of traditional steel reinforcement.

- This is a good idea for low cost economical structure.

- Bamboo reinforcement technique is used for both main and distribution reinforcement as it was same earlier done for steel reinforcement.

- It is three times cheaper then steel reinforcement technique.

- Design principal and calculation done for bamboo reinforcement are taken from US NAVAL CORPS guidelines and references.

- It is clear from results that this bamboo reinforcement technique is absolutely cheaper then steel reinforcement technique especially for single story structure.

- In future it has a great wide scope for designing multi-story structure using bamboo reinforcement.

\section{IV.II. Design of building}

Design of Slab

- Effective span -In case of continuous slab, if the width of the support less than $1 / 12$ of the clear span, the effective span shall be the distance between centre of supports or the clear distance between supports plus the effective depth of the slab, whichever is smaller.

- Limiting stiffness -The ratio of span to effective depth should not exceed 26. Modifications factor for tension reinforcement will be extra.

- Moment and shear coefficient -Same rules as for continuous beams given in clause A-10

- Reinforcement and its arrangement -The rules for main reinforcement and transverse/ distribution reinforcement re the same as discussed for simply supported one way slab. However the code IS456:2000 makes the following recommendations.

\section{Positive moment reinforcement}

At least $1 / 3$ rd positive movement reinforcement in simple members and $1 / 4$ th in continuous member shall extend along the same phase of the member into the member to a length $=\mathrm{Ld} / 3$.

\section{Negative moment reinforcement}

At least 1/3rd of the total reinforcement provided for negative movement at the support shall extend beyond the point of inflexion for a distance not less than the effective depth of the member.

\section{Design of Beam}

- Calculation of constants. -For the given set of stresses, determine $\mathrm{KC}$, JC and RC.

$\mathrm{Kc}=\mathrm{M} \sim \mathrm{cbc} / \mathrm{M} \sim \mathrm{cbc}+\sim \mathrm{st}$

$\mathrm{Jc}=1-(\mathrm{Kc} / 3)$

$\mathrm{Rc}=0.5 * \mathrm{~L} * \mathrm{Kc} \mathrm{Jc}$

- Calculation of bending moment. Assume suitable values of overall depth and breadth of beam, and determine the effective span. Calculate self-weight and total U.D.L. and maximum bending moment in the beam.

- Design of the section. Calculate the effective depth of the beam by the expression:

$\mathrm{d}=[(\mathrm{M}) /(\mathrm{RC} * \mathrm{~b})] 0.5$

- Reinforcement. Calculate the area by the formula.

Ast $=\left[(\mathrm{M}) /\left(\sim \mathrm{st}^{*} \mathrm{Jc} * \mathrm{~d}\right)\right]$ where $\sim \mathrm{st}=$ permissible tensile stress in steel.

- Shear Reinforcement. Calculate the maximum shear force in the beam.

- Check for Development length at the end.

$\mathrm{Ld}<=(\mathrm{M} 1 / \mathrm{V})+\mathrm{L} 0$.

\section{Design of column}

- Determine the Permissible stresses in concrete, longitudinal bars and ties.

- Find super impose load the column is required to carry.

- Determine the area from the following expression - $\mathrm{P}=\sim \mathrm{cc} * \mathrm{Ac}+\sim \mathrm{sc} *$ Asc. 
- After having known the area, determine the dimensions of column. If it is a square of side $b$, then $b=A g$.

- For the given end conditions determine effective length of column. Calculate lef/b ratio to find whether it is a short or long column.

- If lef $/ \mathrm{b}$ ratio $<12$ it will be designed as short column otherwise as long column determine the area of steel Asc.

- Find the diameters of bars used as ties and determine its pitch as per rules.

\section{Design of Footing}

The width $\mathrm{B}$ of the footing will evidently be equal to $\left[\mathrm{W}+\mathrm{W}^{\prime}\right] / \mathrm{qo}$. The thickness is calculated both from the considerations of bending moment as well as punching shear.

- Depth for bending moment.

$\mathrm{d}=[\mathrm{M} / \mathrm{B} * \mathrm{Rc}] 0.5$

- Depth for shear.

$\mathrm{tv}=\mathrm{V} / \mathrm{B}^{*} \mathrm{~d}$

- Steel Reinforcement.

Ast $=\mathrm{M} / \mathrm{tjcd}$

Check for development length.

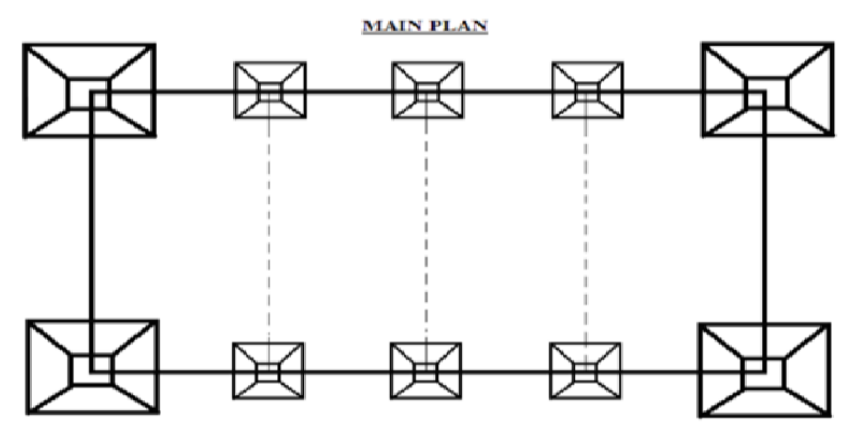

GROUND FLOOR PLAN

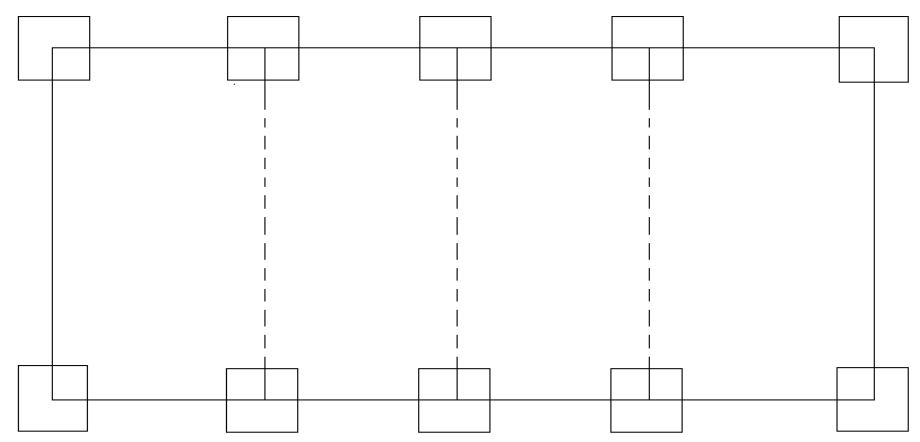

RCC Slab

V. Estimation of Steel Reinforcement

Calculation

\begin{tabular}{|l|l|l|l|l|l|}
\hline $\begin{array}{l}\text { Description } \\
\text { of bar }\end{array}$ & Shape of bending & Length & number & $\begin{array}{l}\text { Total } \\
\text { length } \\
\text { (m) }\end{array}$ & $\begin{array}{l}\text { Weight } \\
\text { (Kg) }\end{array}$ \\
\hline $\begin{array}{l}\text { Main bent } \\
\text { up bar }\end{array}$ & & 3.88 & 34 & 129.2 & $.61 * 129.2=$ \\
\hline L1 & & 3.88 & 34 & 129.2 & 79.75 \\
\hline L1 & & & & & \\
\hline
\end{tabular}




\begin{tabular}{|c|c|c|c|c|}
\hline L1 & 3.88 & 34 & 129.2 & $\begin{array}{l}79.75 \\
319.01 \mathrm{Kg}\end{array}$ \\
\hline \multirow[t]{2}{*}{$\begin{array}{l}\text { Distribution } \\
\text { Bar } 6 \mathrm{~mm} \phi \\
\text { Bars }\end{array}$} & 6.98 & 57 & 397.86 & $\begin{array}{l}.22 * 397.86=88.41 \\
\mathrm{Kg}\end{array}$ \\
\hline & & & $\begin{array}{l}\text { Grand } \\
\text { Total }\end{array}$ & $=407.42 \mathrm{Kg}$ \\
\hline
\end{tabular}

$\mathrm{L} 1=3.9-2 * .025+.42 * .080$

$=3.9-.05+.0336$

$=3.88$

$\mathrm{L} 2=7-2 * .025+.42 * .080$

$=6.98$

No. of bars $=(7 /$ spacing $)+1$

$=(7 / 215)+1$

$=34$

No of distribution bars $=(12 \mathrm{~m} / \mathrm{spacing})+1$

Cost $=50 \mathrm{Rs} / \mathrm{Kg}$

$=50 * 407.42$

$=20371 \mathrm{Rs}$

\begin{tabular}{|l|l|l|l|l|l|}
\hline $\begin{array}{c}\text { RCC Beam Description of } \\
\text { bar }\end{array}$ & Shape of bending & Length & Number & $\begin{array}{l}\text { Total } \\
\text { length }\end{array}$ & Weight \\
\hline Main straight bar & & 6.95 & 2 & 13.9 & $1.58^{*} 13.9$ \\
\hline Main bent up bar & & 7.496 & 1 & 7.496 & $\begin{array}{l}1.58^{*} \\
7.496\end{array}$ \\
\hline Stirrups & & 1.764 & 25 & $\begin{array}{l}42 \\
\text { Total } \\
=63.396\end{array}$ & $\begin{array}{l}1.58^{*} 42 \\
=\text { Total } \\
=100.16 \\
\text { Kg }\end{array}$ \\
\hline
\end{tabular}

Length $\mathrm{L} 1=7-2 * .25$

$=6.95$

$\mathrm{L} 2=6.95+.42 \mathrm{D} * 2$

$=7.496$

Calculation of stirrups

$\mathrm{A} 1=\wedge-2 *$ side cover $-\phi$

$=.7-2 * .025-0.016=.634 \mathrm{~m}$

$\mathrm{A} 2=.25-2 * .025-.016$

$=.184 \mathrm{~m}$, Therefore: $2 *(.634+.184)+8 * \phi=1.764$

Cost $=$ Rs 50 per Kg, Total $=50 * 100.16=5008$ Rs

\section{V.I. RCC Beam 2}

\begin{tabular}{|l|l|l|l|l|l|}
\hline Calculation Description of bar & Shape of bending & Length & number & $\begin{array}{l}\text { Total } \\
\text { length }\end{array}$ & Weight \\
\hline Main straight bar & -2.95 & 2 & 5.90 & $1.58 * 5.90$ \\
\hline Main bent up bar & & 3.496 & 1 & 3.496 & $1.58 * 3.496$ \\
\hline Stirrups & & 0.932 & 25 & $\begin{array}{l}23.3 \\
\text { Total } \\
=52.696\end{array}$ & $\begin{array}{l}1.58 * 23.3 \\
=\text { Total } \\
=83.25 \mathrm{Kg}\end{array}$ \\
\hline
\end{tabular}


Length $\mathrm{L} 1=3-2 * .025=2.95$

$\mathrm{L} 2=2.95+.42 \mathrm{D} * 2=3.496$

Calculation of stirrups

$\mathrm{A} 1=\wedge-2 *$ side cover $-\phi=.242$

$\mathrm{A} 2=.25-2 * .025-.08=.192$, Therefore $=(\mathrm{A} 1+\mathrm{A} 2) 2+8 \phi=.932, \mathrm{Cost}=83.25 * 50=4162.984 \mathrm{Rs}$

\section{V.II. Footing with column Steel reinforcing bar including bending}

$1.8 \mathrm{~mm}$ dia bar $\phi .39 \mathrm{Kg}$ in Base Footing

$\mathrm{L}=1200-2^{*}$ cover, $1200-2 * 25=1.15 \mathrm{M}$, No. of bars $(1200 / 250)+1=5.8 \sigma=\sigma 6$ bars

Weight of steel in base footing $=2 * 6 * 1.15^{*} 0.39=5.38 \mathrm{Kg}, 2.20 \mathrm{~mm}$ dia bar $\phi 2.47 \mathrm{Kg}$ in column above Ground level

$\mathrm{L}=3 \mathrm{~m}$, No. of bar $=(3000 / 250)+1=13$

$13 * 3 * 2.47=96.33 \mathrm{Kg}$, Below Ground Level $=\mathrm{L}=0.2 \mathrm{~m}, 0.2 * 2.47 * 1=0.494 \mathrm{Kg}$

Total steel $=5.38+96.33+.494=102.204 \mathrm{Kg}$

Abstract of cost

Quantity of steel reinforcement bars $=102.204$, Cost Per Kg of steel $=50 \mathrm{Rs} / \mathrm{Kg}$

Amount $=102.204 * 50=5110.2$ Rs

VI. Estimation Of Bamboo Reinforcement

\begin{tabular}{|c|c|c|c|c|}
\hline $\begin{array}{c}\text { Estimation of } \\
\text { Bamboo slab } \\
\text { Description of } \\
\text { bar } \\
\end{array}$ & Shape of bending & Length & Number & $\begin{array}{l}\text { Total } \\
\text { length (M) }\end{array}$ \\
\hline $\begin{array}{l}\text { Main } \\
\text { reinforcement bar } \\
\text { L1 }\end{array}$ & & 3.88 & 34 & 129.2 \\
\hline L1 & & 3.88 & 34 & 129.2 \\
\hline L1 & & 3.88 & 34 & 129.2 \\
\hline L1 & & 3.88 & 34 & 129.2 \\
\hline $\begin{array}{l}\text { Distribution Bar } \\
\text { L2 }\end{array}$ & & 6.98 & 57 & 397.86 \\
\hline & & & & $\begin{array}{l}\text { Total }= \\
914.66 \mathrm{M} \\
\text { Rate }= \\
914.66 * 10 \\
\text { Rs/m }\end{array}$ \\
\hline
\end{tabular}

Calculation

$\mathrm{L} 1=3.9-2 * .025+.42 * .080=3.9-.05+.0336=3.88$

$\mathrm{L} 2=7-2 * .025+.42 * .080=6.98$ '

No. of bars $=(7 /$ spacing $)+1$

$=(7 / 215)+1=34$

No of distribution bars $=(12 \mathrm{~m} / \mathrm{spacing})+1$, Cost $=914.66 * 10 \mathrm{Rs} / \mathrm{m}=9146.6 \mathrm{Rs}$

\begin{tabular}{|l|l|l|l|l|}
\hline \multicolumn{1}{|c|}{ Bamboo Description of bar } & Shape of bending & Length & number & Total length \\
\hline 1 & & 6.95 & 2 & 13.9 \\
\hline 2 & & 7.459 & 1 & 7.459 \\
\hline Stirrups & & 1.704 & 25 & 42.6 \\
\hline
\end{tabular}


Calculation Stirrups

\begin{tabular}{|l|l|l|l|l|}
\hline Description of bar & Shape of bending & Length & number & Total length \\
\hline 1 & 2.95 & 2 & 13.9 \\
\hline 2 & & 3.496 & 1 & 7.496 \\
\hline Stirrups & .96 & 25 & 24 \\
\hline
\end{tabular}

$\mathrm{A} 1=\wedge-2 *$ side cover $-\phi=.3-2 * .025-.015=.235$

$\mathrm{A} 2=.25-2 * .025-.015=.185$

Therefore: $(\mathrm{A} 1+\mathrm{A} 2) 2+8 \phi=.96$, Rate $10 \mathrm{Rs}, \mathrm{Cost}=45.359 * 10=453.59 \mathrm{Rs}$

VI.I. Bamboo reinforcement in column and footing

9.525 Dia Bars in base footing, Length $=1200-2 *$ cover $1200-2 * 25=1.15 \mathrm{~m}$

No. of bars $=(1200 / 250)+1=6$ Bars, $20 \mathrm{~mm}$ dia bars in columns above ground level $\mathrm{L}=3 \mathrm{~m}$

No. of bars $(3000 / 250)+1=1$, below ground level length $=.2 \mathrm{~m}$, No of bars $=1$

Total cost $=2 * 6 * 1.15 * 10+3 * 13 * 10+.2 * 1 * 10=$ Rs 530

VII.I. Result of Analysis

\section{Results and Discussion}

Final analysis on estimation of both steel and bamboo Reinforcement:-

\begin{tabular}{|c|c|c|}
\hline Item & Steel (Rs) & Bamboo (Rs) \\
\hline Slab & 20371 & 9146 \\
\hline Beam 1 & 5008 & 640 \\
\hline Beam 2 & 4162 & 454 \\
\hline Column \& Footing & 5110 & 530 \\
\hline TOTAL & Rs 33,072 & Rs 10,770 \\
\hline
\end{tabular}

\section{VII.II. Discussion}

Comparison between Cost of steel and Bamboo reinforcement concludes with the result that Structures reinforced with bamboo as reinforcement is found cheaper than that of with Steel reinforcement

\section{VIII.I. General Study}

\section{Literature Review}

Building with bamboo looks back on an ancient tradition in the regions in which plant grows in abundance, such as South America, Africa and, in particular, in South-East-Asia. Bamboo is one of the oldest construction materials. There has been a furious construction activity in the developing world, especially India and China, for the last one and a half decades. Although not directly visible, construction industry is one of the most polluting industries in the world. Production of both concrete and steel causes considerable deterioration of the environment.

"BAMBOO AS GREEN ALTERNATIVE TO COCRETE AND STEEL FOR MODERN STRUCTURES" By- Suresh Bhalla (International Congress of Environmental Research, Goa, 18-20 December 2008)

Despite of the long tradition of building with bamboo, the material is not used frequently in modern building constructions. Or can we see a change in the use of bamboo? In the past years architects have been using bamboo in different ways in their designs. From interior finishes to bamboo constructions the application of bamboo in design is still developing and there are more new applications to be expected. Materials that are used in green design are always assessed for their environmental impact. Bamboo can replace concrete, steel or wood, depending on the situation and the application, although more built examples and dissemination is needed. 


\section{VIII.II. Analytical Studies and research}

Tjerk Reijenga "Role of Bamboo in Green Building Design". In this project we are comparing steel reinforcement with bamboo reinforcement, its structural and constructional cost and techniques of replacement of steel with bamboo while reinforcing.

Ghavami (1995) discussed the mechanical properties of Bamboo, specifically pertaining to Bamboo in concrete. This study showed that the ultimate load of a concrete beam reinforced with Bamboo increased $400 \%$ as compared to un-reinforced concrete. It was found that, compared to steel, there was lower bonding between the bamboo and concrete, and the Bamboo had a Modulus of elasticity 1/15 of steel. Bamboo's compressive strength was much lower than its tensile strength, and there was high strength along the fibres, but a low strength transverse to the fibres. Stated is the need for the development of a simple design code for the application of Bamboo as a construction material.

The United States Naval Civil Engineering Laboratory $(1966,2000)$ reported a study providing a set of instructions on how to properly construct a variety of structures and structural elements using Bamboo. This study suggested not to use green, unseasoned Bamboo for general construction, nor to use un-waterproofed Bamboo in concrete. Concerning Bamboo reinforced concrete, it was found that the concrete mix designs may be the same as that used with steel, with a slump as low as workability will allow. It was recommended that the amount of Bamboo reinforcement in concrete be 3-4\% of the concrete's cross-sectional area as the optimum amount. It concludes that Bamboo reinforced concrete is a potential alternative light construction method at a low cost.

Amada et al. (1997) investigated the mechanical and physical properties of Bamboo. They conducted a thorough investigation into the structure and purposes of the nodes, which they found to strengthen the Bamboo Culm. They also commented on the advantage Bamboo has over other natural building materials with its fast growth rate.

Masani (1977) conducted an in-depth study outlining the proper ways to utilize Bamboo in construction. A listing of the positive aspects of Bamboo is given, citing examples pertaining to its economical, mechanical, and environmental properties. When used as reinforcement in concrete, directions are given to insure a better performance, including discussions on waterproofing, pressure-treating, concrete design, and beam design. This study found that the Bamboo reinforcement area should be 5 times the typical steel reinforcement area, and that even when fine cracks develop on the surface of Bamboo, the load carrying capacity of the member is not reduced. The only negative properties of Bamboo given are its susceptibility to attack by insects, fungi and dried bamboo is prone to catch fire.

Amada and Untao (2001) studied the fracture properties of Bamboo. In contradiction to other studies, this study states that the tensile strength of Bamboo fibres almost corresponds to that of steel. The main discovery is that the fracture properties of Bamboo depend upon the origin of fracture. In the nodes, it is found that the average fracture toughness is lower than the minimum value of the entire Culm, suggesting that the fibres in the nodes do not contribute any fracture resistance.

Power (2004) tells of a study conducted by the U.K. Department of International Development in response to a devastating earthquake that killed 40,000 people in Iran. The engineers were looking for cheap earthquake-proof housing to take the place of mud brick. They constructed a prototype Bamboo reinforced concrete house and used an earthquake simulator to find that the house stood sound during a 7.8 (on the Richter scale) earthquake. They found no cracking in the concrete, the Bamboo to be extremely resilient to earthquakes, and the cost to be split in half compared to mud-and-brick construction.

Seinfeld (2001) researched the remarkable current uses of Bamboo around the world. In the United States, it is almost completely used as decoration. A discussion is presented on the astonishing feature Bamboo brings to the table as mentioned in other articles. Another special feature about Bamboo is that harvesting Bamboo does not harm the plant, producing more of its timbers. Bamboo buildings are definitely a prospect of the future in the US; however in Asia, the Pacific islands, and South \& Central America, they are quite traditional. The main prevention of Bamboo structures in America are building codes. There are not standardized codes for buildings of Bamboo though there are attempts towards them. Bamboo is also still being looked at as a way to clean environmental pollution. It is a consumer of Nitrogen, which could soon be part of a huge effort to prevent air pollution.

The American Bamboo Society (2005) provided a very intricate collection of specialized terms followed by their definitions relating to Bamboo. It also has a glossary of questions and answers common to someone new to the topic. These questions ranged from identifying Bamboo, preserving Bamboo, finding help with your Bamboo, to other topics not as closing connected to the research of this project.

A study reported in International Network for Bamboo and Rattan (INBAR) (2002) considered the advantages and disadvantages of Bamboo used as a structural material. The advantages found in their study concluded to be areas of: ecological value, good mechanical properties, social and economic value, and energy consumption. They found disadvantages to be: preservation, fire risk, and natural growth. 
Mardjono (1998) provided research with the effort to give some sort of organization of a system to building with Bamboo between cultures, species, and countries having varying designs. The objective of their research was to improve the functions of Bamboo buildings by this organization to provide privacy, safety, comfort, durability, and accessibility. Overall Bamboo used as a structural material suffers from an incredible disadvantage due to inadequate applied scientific research. They do feel that Bamboo products should be brought to the level of acknowledged and received building materials. The results of their research will be published as a thesis and guide for designing Bamboo structures to be dispersed to people in developing countries.

A study reported in International Standard Organization (ISO) (1999) fashioned lab manual for determining the physical and mechanical properties of Bamboo. The purpose for publishing this manual is first of all so that these methods are available all over the world. Research is done in so many places, very precise, yet is stuck in the laboratories. With this document, the methods are made available. Secondly, this document gives a practical step by step explanation of how to perform each test specifically following the International Standard Complement Document "Determination of Physical and Mechanical Properties of Bamboo." Another complement document is Bamboo Structural Design (1999).

Janseen (2000) conducted her study on building with Bamboo. This book covered a wide variety of aspects of Bamboo going back to the structure of the plant and its natural habitat. It gives calculations to show why it's economically competitive, mechanical properties, its many uses, its natural durability, and the preservation of the Bamboo. In much more detail, it discusses the joints and building with pure Bamboo. In relation to this project, her book does touch on Bamboo used as reinforcement in concrete. Listed in her book are several things that are more of a hassle than steel reinforcement. Of those, the bonding between the Bamboo and concrete is considered the biggest problem due to absorption of water and smooth wall of the Bamboo Culm.

The US Naval Corps is the leading institute in research for bamboo reinforcement techniques and it has developed some tables and graphs

\section{Conclusions and Scope for Future Work}

\section{IX.I Conclusion}

In this project we have opted advanced bamboo reinforcement technique instead of traditional steel reinforcement. This is a good idea for low cost economical structure. Bamboo reinforcement technique is used for both main and distribution reinforcement as it was same earlier done for steel reinforcement. It is three times cheaper then steel reinforcement technique. It is clear from results that this bamboo reinforcement technique is absolutely cheaper then steel reinforcement technique especially for single story structure.

\section{Scope For Future Work}

Bamboo is a versatile material because of its high strength-to-weight ratio, easy workability and availability. The Analysis of the replacement of steel with bamboo as reinforcement shows that reinforcement with bamboo is quite cheaper than that of steel reinforcement. The positive attributes of Bamboo are listed, supporting its environment-friendly nature. But there are some negative attributes of Bamboo were also given, focusing on its tendency to absorb water. Of those, the bonding between the Bamboo and concrete is considered the biggest problem due to absorption of water and smooth wall of the Bamboo Culm. Also there is a need for the development of a simple design code for the application of Bamboo as a Construction material. Several Researches are on going to overcome these problems. Many new techniques are being developed which may make bamboo the best constructional material in future. It has wide scope in Low Cost Constructions.

\section{References}

[1] Bhalla , S., Janssen J.A.J “ Design Bamboo As Green Alterative To Concrete And Steel For Moder Structures.”

[2] Chariar.V.M., "Fabrication and Testing of Jute Reinforced Engineered Bamboo Structural Elements."

[3] Dutta, B.N. "Estimate \& Costing in Civil Engineering."

[4] Francis E. Brink and Paul J. Rush "Bamboo Reinforced Concrete Construction."

[5] Jules.,J. "Designing and Building with Bamboo."

[6] Punamia,B C., Jain, A., Jain,A.K. " RCC Designs (Reinforced Concrete Structure)"

[7] Reijenga,I,T. "The Role of Bamboo in Green Building Design."

[8] Varghese,P.C, "Design of Reinforce Concrete Structure."

[9] $\square$ H. E. Glenn. "Bamboo reinforcement in portland cement concrete,"

[10] E. F. Smith and K. L. Saucier. Vicksburg, Mississippi, "Precast concrete elements with bamboo reinforcement,"

[11] S. R. Mehra and R. G. Ghosh. "Bamboo-reinforced soil-cement," Civil Engineering and Public Works Review, Vol. 60, no. 711, October 1965; vol. 60, no. 712. November 1965.

[12] "Concrete floors on ground," Portland Cement Association Concrete Information, ST-51.

[13] American Concrete Institute. "Building code requirements for reinforced concrete," (ACI 318-56). May 1956.

[14] Department of the Navy, Bureau of Yards and Docks. Design Manual NAVDOCKS DM-2, Structural Engineering. October 1964. 